\title{
The Effect of Western Diet Culture on Chinese Diet Culture
}

\author{
Lijun Yang \\ School of Business and Trade \\ Huanghe Science and Technology College \\ Zhengzhou, China \\ e-mail: 379630960@qq.com
}

\begin{abstract}
Western countries have their own systematic diet culture; China has his own unique and rich diet culture too. However, one phenomenon should not be ignored: nowadays China traditional diet culture has showed new characteristics. The mode of western diet, the diet ideas, diet wares and so on are immersing into Chinese diet culture subconsciously. So it is necessary to analyze the effect of western diet culture on Chinese diet culture and what's the correct attitude we should hold. This article introduces the western diet culture and its characteristics, and then analyzes Chinese traditional diet culture. Thirdly study the effect of western diet culture on Chinese diet culture in detail. Lastly according to the third part get three conclusions: the history of western diet culture's influence on Chinese diet culture; the reason of the large influence of western diet culture; the correct attitude we should hold to the effect: be fully use of the western diet culture to enrich Chinese diet culture on the clear understanding that retain the original excellent tradition of Chinese diet culture, reasonably combine western diet culture with Chinese diet culture.
\end{abstract}

\section{Keywords—western diet culture; effect; Chinese diet culture}

\section{THE WESTERN DIET CULTURE'S CHARACTERISTICS}

So called western diet culture refers to material and spiritual fortune created by westerners in the process of longterm food's production and consumption.

\section{A. Superb Skills in Making Diet}

Westerners strive for perfection of making diet be perfect, both the meals and the beverages are excellent in craftsmanship 、 delicious in flavor. The skills in making the meals are different in accordance with different parts、 quality of the raw materials. Less mixed knives are adopted, the basic shapes of raw materials are simple, the main shapes are big block、 thick slice. The cooking methods are unique, as usual including roast iron plate、 iron grill etc.. The seasoning is very special and they increase the flavor after heating, usually the sauce, spice, wine and dairy products are used as seasoning. Beautiful designs, simple and practical dishing are stressed, the most contents of the dishes are edible. They focus on decorative and edible functions of diet, so the decoration is not the unique aim of the cook.

\section{B. Colourful Diet Custom}

The diet custom is an inheritance and prevailing custom formed by the people in the cooking process from the ancient times. It can be divided into: everyday diet custom, festival diet custom, social contact diet custom, national diet custom, religious diet custom etc. Western diet custom is different for each western nation owns distinct cultures. Ordinarily westerners eat mainly meat and vegetables, and drink coffee and wines. They are used to the individual meal, each of them only eats the diet belonging to him, and it seems very individual and hygienic. The religion affects the festival diet custom largely, thus westerners are accustomed to the regulations of religion.

\section{Various Kinds of Diet}

The West is a multi-nationality area with a long history; Thousands of various meals and drink have been created by the professional chefs and housewives in the West. Different kinds of social backgrounds produce different kinds of meals and local flavors. The kinds of drink mainly include various wine and coffee, such as whisky, brandy, vodka, rum and so on.

\section{Fluctuation of Diet History}

The western diet history is very special, long-term political split and the continuous moving of economic and cultural centre lead to the western diet history is full of unbalanced development pattern, particularly in the important period of history. In ancient times the Italian cuisine was most influential. Italian cuisine was born directly of Greece and Rome, and it was very popular until the end of 16th Century. By virtue of its classical style, the Italian cuisine became the leader of ancient western diet. In modern times the France cuisine is the most famous. It was influenced by the Italian cook deeply and combined his own advantages, so the France flavor was formed. From the 17th century to 19th century France cuisine was the absolute leader of western diet. In contemporary times the most influential diet is the England cuisine and the America cuisine. Although they are also influenced by Italian cuisine and France cuisine more or less, they have combined local flavors and applied the contemporary technology, then the traditional cooking mode and tools have been changed largely, the cooking flavors were formed of their own ${ }^{[1]}$. 


\section{E. Systematic and Classic Diet Books}

Classic diet books are used to record and discuss the cooking. Westerners have being paid attention to the analytic and logical thinking, the western chefs own high social rank and certain cultural cultivation as well, so the western classic diet books' authors include chefs and other professions, the contents include technical and specific experiential generalization, scientific and generalized analyses. The classic diet books can be divided into cooking techniques, cooking cultures and art, cooking science and integration.

\section{F. Unique Diet Science}

The western diet science shows its unique diet thinking and scientific management. Because western philosophy believes the isolation and opposite exist between the entity and the emptiness, the unique diet science has been formed in western country including ecological idea, rational and balanced nutritional idea and prominent personalities of delicious diet idea. The diet choice should meet the individual need, through cooking process give prominence to the special flavor of every raw material. In addition the standardization of cooking, stabilization of products' quality, use of the industrial production and operation at scale, the western diet has developed well.

\section{Chinese Diet Culture}

\section{A. Development of Chinese Diet Culture}

Chinese diet culture has undergone more than 1.7 million years. We can divide it into 4 stages: raw diet stage, prepared diet stage, natural cooking stage, scientific cooking stage, there are more than 60 thousand of traditional cooking, 20 thousand of industrial diet and gorgeous flavors ${ }^{[2]}$

Analyzed from the connotation, Chinese diet culture includes development and utilization of diet resource, use and creation of diet wares, production and consumption of food, service and reception of catering, management of catering industry and diet industry etc. It has showed different cultural flavors and various values.

\section{B. Influence of Chinese Diet Culture}

Chinese diet culture pays more attention to the medicated alimentation and the edible tonic, the vegetarian is more beneficial than meat in their opinion. It has affected directly Japan, Mongolia, Korea, ROK, Thailand, Singapore etc, and the core of the eastern diet culture. In the meantime it has indirectly affected the Europe, the America, the Africa and the Oceania. Chinese vegetarian culture, tea culture, vinegar, soy sauce, noodles food, ceramic diet wares and beans etc, are very popular with all the people in the world. Chinese tea is the famous beverage in the world and has become one of the three most popular soft drinks in the world (tea, coffee and cocoa). Nowadays more than 50 countries are planting the tea which all come from China. China has been well known as the motherland of tea.

\section{Characteristics of Chinese Diet Culture}

In brief, Chinese diet culture shows the wide ken, high level, and delicious taste. The development of diet resource, diet research and making, diet recuperation have been created and accumulated in the process of every Chinese nationality's production and life practice over 1 million years. Although it has affected other countries in the world, it also be influenced by the other countries, especially the West.

\section{The EFFECT OF WESTERn DIET CULTURE ON CHINESE DiET CULTURE}

We should be sure that economic and cultural communication between China and the West results in western diet culture enters into China. Western diet culture affects widely Chinese diet culture.

\section{A. Enriching Chinese Diet Culture}

In the period of Han Dynasty or Tang Dynasty the western diet entered into China and enriched Chinese diet life. In modern times, beer, beverage, cake and various western snacks were quite popular with Chinese, the rhythm of Chinese life had been sped up as well. In addition Chinese cook the western diet with their methods of cooking or cook their diet with Western modes, the combination of China and the West had been accepted, such as the "Grilled Beef", "Prawns cooked by Western style" are all the excellent combination and were found in the diet list of China at the beginning of 20th Century. Chinese diet culture has developed greatly through combining the essence of diet culture of China and the West in modern times. Modern western diet culture was immersed into Chinese diet culture gradually after going through the process of confliction with the later. New cooking methods have been created which not only keep both parties' original nature, but also improve the quality. Chinese modern diet culture has formed which includes traditional characteristics and external style but not a simple combination of them, it is the direction of Chinese diet culture development.

\section{B. Improving Chinese Traditional Banquet Mode}

China's traditional banquet is sharing the same diet. When the festival is coming, Chinese will give a large dinner in honor of friends and relatives. Although it is very warm and, intimated and friendly, it is inappropriate considering health and expenses. It reflects Chinese old philosophy has made great influence on diet culture, diet culture contains the mentality of nation after all, and the most important thing is the harmony in their opinion. The West is popular with individual meal and buffet, this mode is economical and can meet the requirement of social communication. Buffet is convenient to communicate with other people and shows the Westerners' demand of personality. Different modes of diet indicate incontestably different national characteristics formed by culture. After entering into the mid of 19th century, China's intelligentsia began to spring up the activity of banquet's improvement because of the effect of western culture, they made an excellent conglomeration of banquet in the East and West. Until today even in many formal occasions Chinese have taken the individual meal. China's mode of traditional banquet has been changed unavoidably. 


\section{Paying More Attention to Cooking Science}

1) Chinese traditional cooking modes stressed on the whole effect of diet, and the flavor is the first. We can find the rich harmonious color of Chinese diet. However the western cooking methods pay more attention to the nutrition and the health and less attention to the flavors. The flavor is more single than Chinese diet but the nutrition is more apparent. Along with the frequent communication between China and the West in modern times, Chinese have begun to study the West's cooking methods, analyze theoretically traditional cooking methods and diet ingredients. Cooking methods of the East and the West are continually infiltrating one another and offsetting one's weakness scientifically ${ }^{[3]}$.

2) Chinese people pursue more nutrition and good atmosphere of dinner. Considering the diet tradition custom, western diets are mainly the meat of high protein, high fattiness and high calorie, but the carbohydrates and cellulose are less. Chinese used to take in the calorie mainly from the cereals. Different diet cultures lead to different effect. Westerners are easy to suffer from obesity, diabetes mellitus, heart disease, high blood pressure and cancer, but many Chinese people are short of nutrition, so nowadays Chinese people has begun to eat more meat than before. Regarding the cooking methods, the West adopts the machines to cook at scale and demands nutrition, convenience and promptness, Chinese diet pays attention to the refinement and demands the combination of color, flavor and form. As to diet environment and mode of services, the western diet requires the neat and tidy, excellent service, novel designs, gentle environment and clear style, all the above meet the demand of modern life pace and the youth's requirements in China, so only this can win the popular of Chinese customers.

3) Chinese people's eating modes are more healthy. The structure of diet shows the national habit of life. The structure of diet consists of national habit, geographic climate, production of the areas and the methods of cooking. The dinner wares of western diet mainly are the knives and forks, then directly decide the form of good individual meal. The individual meal come from the original cut of diet, whatever we can see this kind of eating and cooking are very scientific, it is good for choice of individual flavor, and increase the freedom of eating, avoid unnecessary waste and avoid the opportunity of germ's cross infection. So intelligent Chinese people have realized the advantages of the individual flavor and to some extent the ideas of Chinese diet colure have been affected $^{[4]}$

\section{Affecings Largely Chinese Everyday Diet Custom}

In old times westerners mainly developed animal husbandry, so almost all the western diet contained the meat. In modern times, plant breeding increased, but the proportion of meat to vegetarian was higher than that of China. Because the meat is naturally delicious, so it is not necessary for westerners to enrich the flavors of the food. The West pursued quantity of diet wares owned and whether it is luxury. However Chinese ate more quantity of vegetarian than meat because of the mode of production and diet healthy idea in ancient times. Accompanied by rising life level and change mode of life, Chinese rhythm of life is becoming quicker, so people require higher efficiency of life than before. Meanwhile more western diet culture has been introduced into China, western everyday diets, especially the fast food, affect Chinese habit of diet and change Chinese traditional diet ideas. Chinese traditional diet culture has been affected greatly. At the recent years, western fast diet has been developing quickly, such as the following famous diet brands: KFC、McDonald、Italian Pizza and Hut have spread all over the China. Now Chinese have changed their ideas of traditional everyday diet custom and are aware of more reasonable diet ideas: vegetarian and meat are all important, the key is the proportion of them. The western diet has its own procedures of placing dishes on the table. First place the soup, then the cold dish followed by the hot dish. The hot dish is fish first, then meat, vegetarian and sweet, at last coffee etc. Chinese Guangzhou cuisine is affected deeply by this mode and has already developed the same procedure of placing dishes on the table as the West.

\section{E. Effect of Western Festival Diet Custom on Chinese}

With the development of globalization some western festival diet custom has been introduced into China, thus Chinese diet custom has formed different festival atmosphere. The important festivals of China are Tomb-sweeping Festival, Dragon Boat Festival, Moon Festival, Double-ninth Day, Lantern Festival, Spring Festival. Western important festivals are Good Friday, Easter, April Fool's Day, All Saints' Day, Thanksgiving, Christmas.

1) Thanksgiving Day and Moon Festival. Thanksgiving Day was created by America, Americans feel very warm when the Thanksgiving Day is coming, and diets of that day are paid the best attention. Traditional dinner is the roast turkey at the Thanksgiving Day. Before being toasted, the inner of turkeys will be filled with condiments and stuffing, the stuffing includes corn bread, white bread, and celery etc. and all have been torn already. In addition internal organs of the turkey which have been put out can be boiled for gravy. Another kind of sauce is cranberry sauce, other cooking preparations include roast mashed potatoes, roast sweet potato, green peas, biscuits etc. The last sweets are the claptrap pumpkin pies. Then at the evening of that day, all households without exception have the rich banquet. Chinese Moon Festival stands for the same perfect conjugal bliss and family reunion as the West. But Chinese traditional diet is the moon cake. The moon cake has become a token of Moon Festival. The classic scenes are just moon cakes and bright moon. Nowadays especially the youths pay less attention to this traditional diet custom than the old men, they will choose one western restaurants or snack bar with their friends or schoolmates, even they prefer roast turkeys to moon cakes. Because moon cakes are too sweet to eat more, generally speaking one is enough. Although the festival can not be neglected as usual, the festival diet custom has more or less been influenced by the West.

2) Christmas and Chinese diet culture. Westerners will be busy at Merry Christmas day, for getting a better festival many families always are occupied with purchasing all kinds of festival wares and Christmas diet at the beginning of December. At the evening of December 24th, all members of the family will reunite and have Christmas super. The indispensable diet is the roast turkey, after super there are plums、 pudding etc. 
They believe after they eat the food, they will receive good fortune and great profit. Of course different western places have different diet custom. Australians will go to the forest with the beverage and make a picnic at that evening. After eating, they begin to dance until the deep night. Besides the roast turkey there is another special diet of American Christmas super-grilled maize porridge covered by butter and put into some fruit. In Denmark at the beginning of Christmas supper, people have to eat first a copy of almond pudding, then the other diet will be followed. In conclusion white Christmas stands for luck, but red symbolizes the luck in China. Before the 21 st century, the Christmas influenced the Chinese life and diet culture relatively little. But in these years the effect of Christmas is more and more comprehensive. Almost one month before Christmas, supermarkets and shopping malls will sell various kinds of Christmas gifts and decorations, such as Christmas trees, Christmas cards etc. And many people will have a rich super the similar with the West ${ }^{[5]}$.

\section{F. History of Western Diet Culure's Influence on Chinese}

The diet is the forerunner of culture and the culture must be broadcasted and communicated, so the western diet has affected China long time ago. The western diet has become another flavor which the Chinese can taste. A famous Italian traveler named Marco Polo traveled in China; he had taken many modes of European cooking to China. Since Opium War of 1840, each port of cities had been opened and each Concession had come out, the western restaurants were followed and developed very quickly. At the beginning of 20th century, Chinese people lifted the fashion of eating western food, it showed the further development of Chinese western diet industry. Until the 1950's, the friendly countries which contact with China increased more, the management of western diet became active. The revolution and open bring the new vigor to the Chinese diet industry, some restaurants of joint venture come out continuously, many advanced western kitchen utensils and methods of processing have been introduced, the cooking level of Chinese diet has been improved greatly, thus we can see the large influence of western diet culture.

\section{CONCLUSION}

Diet is the important content of human social life, the collection of raw materials, production, storage, sales and cooking, all reflect ability of creation and philosophic ideas of different countries. In addition different areas, nationalities and countries have their own individual and special local culture, so the difference exists inevitably.

The combination of Western diet culture and Chinese diet culture is reasonable. Because different social history, all kinds of national cultural tradition and various characteristics of areas lead to the different background between Chinese diet culture and the Western diet culture, but generally speaking, the connotation of eating can not be changed because of the differences in essence. Although most of characteristics of the western diet culture and Chinese diet culture are changeable, they have some relative stability of common aspects. Seen from the developing tendency of contemporary international diet industry, Chinese diet culture and the Western diet culture can make full use of the advantages and bypass the disadvantages, and then improve themselves step by step. All the following aspects: varieties' pursuing, balance of nutrition, reasonable collocation, health stressed have become the common ideas of Chinese diet science and the western diet science, the western diet culture affects Chinese diet culture largely, and on the contrary Chinese diet culture can affect the western diet culture too, the effect is mutual, and the above common ideas are the important base between Chinese and the western diet culture's communication and mixture. Only through communication Chinese diet culture can be positively affected by the western diet culture and understand further them, only the deep understanding can promote the development. At this moment the science and technology and the international communication in the world have been strengthening continuously, the fresh ideas and rich contents of western diet culture have poured the infinite vitality into Chinese diet culture.

After China has entered into WTO, the biggest combination of Chinese diet culture and the western diet culture will come out to the largest extent; the revolution of eating should happen naturally in China. At this moment, the intercourse of international economics and trade will be more frequent than before, and the speed of globalization is faster, many kinds of western foods are certain to be sold in Chinese diet market which affect strongly the Chinese traditional diet custom. So Chinese diet industry must face big challenges, China should utilize the opportunity but not evasion.

In a word, the western diet culture has promoted better development level of Chinese diet culture, we should absorb reasonably the essence of the western diet culture, and then improve quality and popularity of the Chinese diet culture.

\section{ACKNOWLEDGMENT}

I would like to give my heartfelt thanks to many people for their help in my academic studies over the past years.

My deepest gratitude to my family, thanks for their kindness, patience, encouragement. Thanks to my school that has give me this delicious opportunity. And thanks to my dear friends who have given their great help to me in my research.

\section{REFERENCES}

[1] DuLi, SunJunxiu.Western Diet Culture[M].BeiJing: Publishing House of China Light Industry, 2006.

[2] Patton,M.Q. The Change of Western diet Culture.[N].China Daily, 2006-7-1(A2).

[3] HuZishan. China Diet Culture[M]. BeiJing: Publishing House of Current Events, 2005.

[4] LiWeibing, HuaGanlin. An Introduction to China Diet Culture[M]. BeiJing: Publishing House of China Trade, 2006.

[5] WangRenxiang. Food is No. 1 need-China Diet Culture[M]. ShanDong: Publishing House of JiNan, 2004 